\title{
Risk of bleeding associated with combined use of selective serotonin reuptake inhibitors and antiplatelet therapy following acute myocardial infarction
}

\author{
Christopher Labos MD CM, Kaberi Dasgupta MD MSc, Hacene Nedjar MSc, Gustavo Turecki MD PhD, \\ Elham Rahme PhD
}

See related commentary by Juurlink on page 1819 and at www.cmaj.ca/lookup/doi/10.1503/cmaj.111576

\begin{abstract}
Background: Patients prescribed antiplatelet treatment to prevent recurrent acute myocardial infarction are often also given a selective serotonin reuptake inhibitor (SSRI) to treat coexisting depression. Use of either treatment may increase the risk of bleeding. We assessed the risk of bleeding among patients taking both medications following acute myocardial infarction.
\end{abstract}

Methods: We conducted a retrospective cohort study using hospital discharge abstracts, physician billing information, medication reimbursement claims and demographic data from provincial health services administrative databases. We included patients 50 years of age or older who were discharged from hospital with antiplatelet therapy following acute myocardial infarction between January 1998 and March 2007. Patients were followed until admission to hospital due to a bleeding episode, admission to hospital due to recurrent acute myocardial infarction, death or the end of the study period.
Results: The 27058 patients in the cohort received the following medications at discharge: acetylsalicylic acid (ASA) ( $n=14426$ ); clopidogrel $(n=2467)$, ASA and clopidogrel $(n=9475)$; ASA and an SSRI $(n=406) ;$ ASA, clopidogrel and an SSRI ( $n=239$ ); or clopidogrel and an SSRI $(n=45)$. Compared with ASA use alone, the combined use of an SSRI with antiplatelet therapy was associated with an increased risk of bleeding (ASA and SSRI: hazard ratio [HR] 1.42, 95\% confidence interval $[\mathrm{Cl}] 1.08-1.87$; ASA, clopidogrel and SSRI: HR $2.35,95 \% \mathrm{CI}$ 1.61-3.42). Compared with dual antiplatelet therapy alone (ASA and clopidogrel), combined use of an SSRI and dual antiplatelet therapy was associated with an increased risk of bleeding (HR 1.57, 95\% Cl 1.07-2.32).

Interpretation: Patients taking an SSRI together with ASA or dual antiplatelet therapy following acute myocardial infarction were at increased risk of bleeding.
Competing interests: None declared.

This article has been peer reviewed.

Correspondence to:

Dr. Elham Rahme,

elham.rahme@mcgill.ca

CMAJ 2011. DOI:10.1503 /cmaj.100912

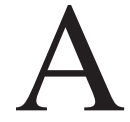
ntiplatelet agents such as acetylsalicylic acid (ASA) and clopidogrel are a mainstay of therapy following acute myocardial infarction. These agents are effective in reducing the risk of recurrent acute myocardial infarction and other cardiovascular events, with the potential for additive benefit when used in combination. ${ }^{1-3}$ The risk of bleeding associated with their use, however, is of concern..$^{46}$ This risk may be increased further by the frequent concomitant use of other medications associated with an increased risk of bleeding, such as anticoagulant therapy ${ }^{7}$ and selective serotonin reuptake inhibitors (SSRIs).

Up to $20 \%$ of patients with cardiovascular disease experience depression and are most often prescribed an SSRI. ${ }^{8-13}$ The vast majority of these patients also use antiplatelet therapy.
The risk of bleeding associated with combining SSRI therapy with single or dual antiplatelet therapy is uncertain. Two large clinical trials that examined SSRI use following acute myocardial infarction did not specifically report on the risk of bleeding,,$^{14,15}$ and earlier studies suggested no increase in risk associated with SSRI therapy combined with single-agent antiplatelet therapy. ${ }^{16,17}$

SSRI use itself has been associated with an increased risk of bleeding, particularly during the first month of use. ${ }^{18}$ The inhibition of serotonin transporters by SSRIs is thought to be responsible for the risk of bleeding. ${ }^{19}$ Platelets release serotonin at sites of bleeding and vascular damage; however, they do not synthesize serotonin and instead acquire it from the blood and store it. ${ }^{19,20}$ By this mechanism, SSRIs may also 
worsen the bleeding caused by ASA and clopidogrel. ${ }^{19,20}$ Inhibition of cytochrome $\mathrm{P} 450$ by certain SSRIs has also been associated with increased risk of drug interaction causing bleeding: ${ }^{21}$ however, data on this issue are scarce.

We examined the risk of bleeding associated with the use of SSRIs when combined with single and dual antiplatelet therapy among patients following acute myocardial infarction.

\section{Methods}

\section{Study population and data sources}

We conducted a population-based, retrospective cohort study using hospital discharge abstracts, physician billing information, medication reimbursement claims and demographic data from the provincial health services administrative databases in Quebec for the period January 1997 to August 2007. In this Canadian province, coverage for outpatient and inpatient physician services is provided for the entire population (about 7.5 million people). In addition, people aged 65 years and older (more than 965000 ), people who receive social assistance (more than 500 000) and those who do not have collective private drug insurance (about 1.7 million), such as self-employed individuals, have their prescription drugs covered by the provincial government. The administrative databases are linkable through a unique patient identifier. We obtained permission to link the data from the ethics board in Quebec (Commission d'accès à l'information).

\section{Inclusion and exclusion criteria}

We included patients 50 years of age and older who were discharged from hospital between January 1998 and March 2007 with a primary diagnosis of acute myocardial infarction (International Classification of Diseases 9th revision code 410.x [before April 2006] or 10th revision code I21.x). For patients who were admitted more than once because of acute myocardial infarction during this period, we included only the first admission. We excluded patients who had been admitted to hospital because of acute myocardial infarction or gastrointestinal bleeding during the year before the discharge date, and those with any bleeding episode during the index admission. Only patients who were discharged home were included, because medication data were available only for such patients.

\section{Patient characteristics at discharge}

We obtained data on the following patient characteristics assessed at hospital discharge: age, sex, comorbid conditions (diabetes, cancer, renal failure, congestive heart failure, and anemia or other hematologic disease [as assessed from diagnoses in the hospital discharge abstracts]) and cardiovascular procedures during the index admission (percutaneous transluminal coronary angioplasty, coronary artery bypass surgery or cardiovascular surgery). Physician billing information in the year before the index admission was reviewed to assess history of gastrointestinal events (diagnosis of ulcer, upper or lower gastrointestinal investigations, use of Hp-PAC to treat Helicobacter pylori infection, and visits to gastroenterologists), history of hemorrhagic stroke, and other bleeding. We also obtained data on the following prescriptions dispensed at discharge: anticoagulants, corticosteroids, traditional nonsteroidal anti-inflammatory drugs, COX-2 (cyclooxygenase-2) inhibitors and proton pump inhibitors.

\section{Definition of exposure episodes}

Patients were separated into six exposure categories according to study medication(s) dispensed: three categories for antiplatelet therapy (ASA alone; clopidogrel alone; and ASA and clopidogrel together), and three for antiplatelet therapy combined with an SSRI (the three above categories combined with an SSRI). The SSRIs studied were citalopram, escitalopram, fluoxetine, fluvoxamine, paroxetine and sertraline. Periods when patients were not in any of these six exposure categories were excluded from the analyses (see "Statistical analysis").

Patients were considered exposed to a medication during the days supplied for that medication plus a grace period of seven days. For example, a patient who was supplied 30 days of clopidogrel and, on day 10, was supplied 30 days of an SSRI was included in the clopidogrel-only category from day 1 to 10 , the clopidogrel and SSRI category from day 11 to 37 , and the SSRIonly category from day 38 to 47 . Each patient may have been included in more than one exposure category if he or she stopped or changed treatment during follow-up.

Patients were followed until admission to hospital due to a bleeding episode, admission to hospital due to recurrent acute myocardial infarction, death or the end of the study period (August 2007).

\section{Definition of outcome}

Bleeding was defined as a bleeding episode (gastrointestinal bleeding, hemorrhagic stroke or other bleeding) that either necessitated admission to hospital or occurred in-hospital during follow-up. Bleeding was identified using primary or secondary hospital discharge diagnoses 
(Appendix 1, available at www.cmaj.ca/lookup /suppl/doi:10.1503/cmaj.100912/-/DC1).

\section{Statistical analysis}

We used polytomous logistic regression models to compare patient characteristics between exposure categories. All patient characteristics were initially included in the models. A backward selection was used whereby a variable that was not significant at the 0.10 level was removed from the model. Multicolinearity was assessed using the variance inflation factor. A factor of 10 or greater indicates multicolinearity. ${ }^{22} \mathrm{We}$ examined the goodness-of-fit of the model using the $\mathrm{C}$ statistic ${ }^{23}$ and receiveroperating-characteristics curves plotted for SSRI and ASA versus ASA alone, and for SSRI, ASA and clopidogrel versus ASA alone. A larger value of $C$ indicates a better fit.

We constructed Cox regression models to examine the association between exposure to study drugs and risk of bleeding during followup, with time-dependent exposure adjusted for patient characteristics and comorbid conditions. A backward selection was used whereby we removed variables that were not significant at the 0.10 level and whose removal from the model did not alter the estimate of the variable of interest (exposure to a study drug) by more than $10 \%$. Periods when patients were not in any of the exposure categories were excluded from the model to facilitate the analysis. Therefore, discontinuous periods were considered. ${ }^{24}$ Hazard ratios (HRs) with 95\% confidence intervals (CIs) are reported.

We conducted several sensitivity analyses to assess the robustness of the results to the methods used and potential drug-drug interactions. First, we restricted the outcome to gastrointestinal bleeding. Second, we excluded patients who had any bleeding episode in the year before the index admission. Third, because the SSRIs included in our study had high (fluoxetine, paroxetine and sertraline) and intermediate (citalopram, escitalopram and fluvoxamine) affinity to serotonin transporters, we investigated the risk of bleeding by SSRI affinity. ${ }^{25}$ Fourth, we investigated the risk of bleeding associated with use of antidepressants other than SSRIs. In a fifth analysis, we excluded patients who were using SSRIs or proton pump inhibitors with clopidogrel, because SSRIs, especially fluoxetine and sertraline, as well as proton pump inhibitors may inhibit activation of clopidogrel. ${ }^{26-29}$ Sixth, we removed the use of anticoagulants from the models to investigate the possibility of over-adjustment. Finally, we conducted an analysis in which we adjusted for Charlson Comorbidity Index scores. ${ }^{30}$

\section{Results}

\section{Study population}

Our cohort included 27058 patients. More than half were taking ASA alone, and about $3 \%$ were taking an SSRI in combination with antiplatelet therapy at discharge (Figure 1, Table 1).

Compared with patients who were taking ASA alone, those taking ASA and an SSRI were more likely to be older, to have renal failure, to have taken antihypertensive agents or antidepressants in the year before the index admission, and to be taking a corticosteroid (Table 2). Compared with patients taking dual antiplatelet therapy (ASA and clopidogrel), those taking dual antiplatelet therapy and an SSRI were more likely to be older, to have taken antihyperglycemic medications or antidepressants in the year before the index admission, and to have anemia or another hematologic disease (Table 2).

\section{Risk of bleeding associated with exposure to study drugs}

The periods included in the analyses totalled 80991 patient-years, during which 1070 episodes of bleeding occurred (Table 3 ).

After adjustment for baseline patient characteristics, we found that the use of an SSRI combined with any form of antiplatelet therapy was

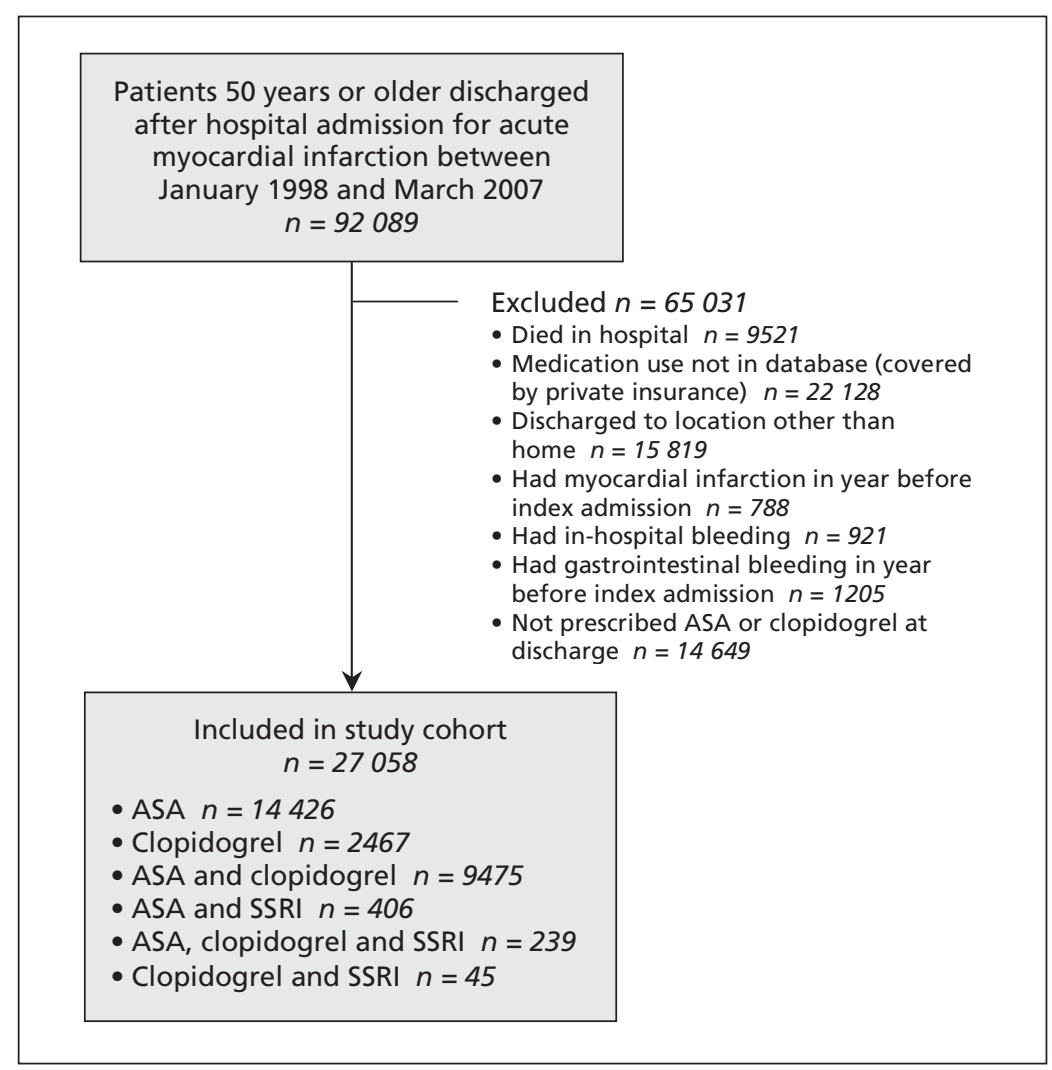

Figure 1: Selection of patients for the study. ASA = acetylsalicylic acid, SSRI = selective serotonin reuptake inhibitor. 
associated with an increased risk of bleeding compared with ASA use alone (ASA and SSRI: HR 1.42, 95\% CI 1.08-1.87; ASA, clopidogrel and SSRI: HR 2.35, 95\% CI 1.61-3.42) (Figure 2). The combination of clopidogrel and an SSRI appeared to have an increased risk of bleeding compared with clopidogrel alone, but the confidence interval was too wide for firm conclusions (HR 1.54, 95\% CI 0.70-3.39). The combination of SSRl with dual antiplatelet therapy increased the risk of bleeding compared with dual antiplatelet therapy alone (HR 1.57, 95\% CI

Table 1: Characteristics of patients discharged from hospital with antiplatelet therapy following acute myocardial infarction between January 1998 and March 2007, by antiplatelet therapy at discharge and receipt of selective serotinin reuptake inhibitor (SSRI)

Antiplatelet and SSRI therapy; \% of patients*

\begin{tabular}{|c|c|c|c|c|c|c|}
\hline \multirow[b]{2}{*}{ Characteristic } & \multicolumn{6}{|c|}{ Antiplatelet and SSRI therapy; \% of patients* } \\
\hline & $\begin{array}{c}\text { ASA } \\
n=14426\end{array}$ & $\begin{array}{c}\text { Clopidogrel } \\
n=2467\end{array}$ & $\begin{array}{c}\text { ASA + } \\
\text { clopidogrel } \\
n=9475\end{array}$ & $\begin{array}{c}A S A+S S R I \\
n=406\end{array}$ & $\begin{array}{c}\text { ASA + } \\
\text { clopidogrel } \\
+ \text { SSRI } \\
n=239\end{array}$ & $\begin{array}{c}\text { Clopidogrel } \\
\quad+\text { SSRI } \\
n=45\end{array}$ \\
\hline Age, yr, mean (SD) & $72(11)$ & $72(10)$ & $69(10)$ & $75(11)$ & $72(11)$ & $76(9)$ \\
\hline Sex, female, \% & 43.2 & 40.4 & 36.2 & 62.1 & 50.8 & 57.8 \\
\hline \multicolumn{7}{|l|}{ Comorbid condition } \\
\hline Congestive heart failure & 29.7 & 24.7 & 20.5 & 38.4 & 32.2 & 42.2 \\
\hline Cancer & 4.1 & 4.0 & 3.3 & 4.9 & 1.7 & 2.2 \\
\hline Renal failure & 5.9 & 5.9 & 4.5 & 13.1 & 12.1 & 15.6 \\
\hline Anemia or other hematologic disease & 16.5 & 17.7 & 12.3 & 28.1 & 26.8 & 31.1 \\
\hline \multicolumn{7}{|l|}{$\begin{array}{l}\text { Cardiovascular procedure during index } \\
\text { admission }\end{array}$} \\
\hline Cardiovascular surgery & 1.8 & 2.9 & 1.5 & 1.0 & 3.3 & 2.2 \\
\hline Angioplasty & 4.1 & 22.7 & 29.8 & 3.0 & 21.3 & 11.1 \\
\hline Coronary artery bypass surgery & 0.5 & 1.0 & 0.2 & 0 & 2.1 & 0 \\
\hline \multicolumn{7}{|l|}{$\begin{array}{l}\text { History of gastrointestinal event } \\
\text { in prior year }\end{array}$} \\
\hline Diagnosis of peptic ulcer disease & 0.71 & 1.2 & 0.80 & 1.7 & 0.84 & 0 \\
\hline Gastroscopy & 8.4 & 7.5 & 4.7 & 12.3 & 8.4 & 4.4 \\
\hline Use of gastroprotective agent† & 18.8 & 17.2 & 20.5 & 39.2 & 41.0 & 37.8 \\
\hline $\begin{array}{l}\text { Use of Hp-PAC to treat Helicobacter } \\
\text { pylori infection }\end{array}$ & 0.19 & 0.32 & 0.23 & 0.99 & 0.42 & 0.0 \\
\hline Visit to gastroenterologist & 9.5 & 10.5 & 8.2 & 13.1 & 13.8 & 20.0 \\
\hline \multicolumn{7}{|l|}{ History of bleeding in prior year } \\
\hline Hemorrhagic stroke & 0.08 & 0.12 & 0.03 & 0 & 0 & 0 \\
\hline $\begin{array}{l}\text { Non-gastrointestinal bleeding } \\
\text { necessitating hospital admission }\end{array}$ & 0.37 & 0.36 & 0.22 & 0.49 & 0.84 & 0 \\
\hline \multicolumn{7}{|l|}{ Medication use in prior year } \\
\hline Antihyperglycemic agent & 19.7 & 26.4 & 17.3 & 25.4 & 31.8 & 28.9 \\
\hline Antihypertensive agent & 61.3 & 79.7 & 56.8 & 80.1 & 76.2 & 75.6 \\
\hline Antidepressant & 11.8 & 15.3 & 11.5 & 84.0 & 87.5 & 82.2 \\
\hline \multicolumn{7}{|l|}{ Medication use at discharge } \\
\hline Anticoagulant & 7.2 & 8.6 & 5.8 & 7.6 & 3.8 & 8.9 \\
\hline $\begin{array}{l}\text { Nonselective nonsteroidal } \\
\text { anti-inflammatory drug }\end{array}$ & 0.79 & 0.24 & 0.55 & 0.99 & 0 & 0 \\
\hline Corticosteroid & 2.1 & 1.4 & 1.6 & 5.9 & 4.2 & 6.7 \\
\hline COX-2 inhibitor & 1.1 & 0.61 & 0.85 & 2.7 & 3.3 & 2.2 \\
\hline $\begin{array}{l}\text { Antiplatelet agent other than ASA } \\
\text { and clopidogrel }\end{array}$ & 0.5 & 0.61 & 0.23 & 1.2 & 0.4 & 2.2 \\
\hline
\end{tabular}


1.07-2.32). The risk of bleeding associated with clopidogrel use was similar to that associated with ASA alone (HR 1.15, 95\% CI 0.87-1.51). The combined use of clopidogrel and ASA increased the risk of bleeding beyond that of ASA alone by $49 \%$ (HR 1.49, 95\% CI $1.28-$ 1.75) (Figure 2).

\section{Risk of bleeding associated with other patient characteristics}

Patient characteristics that were independently associated with an increased risk of bleeding were age, cancer, renal failure, congestive heart failure, anemia or other hematologic disease, use of anticoagulants or corticosteroids at dis- charge, prior use of antihyperglycemic or antihypertensive agents, history of peptic ulcer disease, history of bleeding other than gastrointestinal bleeding and prior visit to gastroenterologist (Figure 3). Women and patients who underwent percutaneous transluminal coronary angioplasty appeared to be at lower risk of bleeding.

\section{Sensitivity analyses}

When we restricted the outcome to gastrointestinal bleeding, the results were similar to those of the main analysis (ASA and SSRI v. ASA alone: HR 1.50, 95\% CI 1.05-2.15; ASA, clopidogrel and SSRI v. ASA alone: HR 3.11, 95\% CI 2.00-

Table 2: Patient characteristics associated with the use of antiplatelet medications and selective serotonin reuptake inhibitors (SSRIs)

\begin{tabular}{|c|c|c|c|c|c|}
\hline \multirow[b]{2}{*}{ Characteristic } & \multicolumn{5}{|c|}{ Antiplatelet and SSRI therapy; adjusted OR* $(95 \% \mathrm{Cl})$} \\
\hline & $\begin{array}{l}\text { Clopidogrel } \\
\text { v. ASA }\end{array}$ & $\begin{array}{c}\text { Clopidogrel + ASA } \\
\text { v. ASA }\end{array}$ & $\begin{array}{l}\text { ASA + SSRI } \\
\text { v. ASA }\end{array}$ & $\begin{array}{l}\text { Clopidogrel } \\
\quad+\text { SSRI } \\
\text { v. clopidogrel }\end{array}$ & $\begin{array}{c}\text { ASA + } \\
\text { clopidogrel + SSRI } \\
\text { v. clopidogrel + ASA }\end{array}$ \\
\hline Age (per 10-yr increase) & $0.94(0.90-0.98)$ & $0.83(0.80-0.85)$ & $1.18(1.06-1.32)$ & $1.55(1.12-2.16)$ & $1.22(1.06-1.40)$ \\
\hline Female sex & $0.83(0.76-0.91)$ & $0.88(0.83-0.94)$ & $1.17(0.94-1.45)$ & $1.16(0.62-2.16)$ & $0.89(0.68-1.17)$ \\
\hline \multicolumn{6}{|l|}{ Comorbid condition } \\
\hline Congestive heart failure & $0.69(0.63-0.77)$ & $0.69(0.64-0.74)$ & $1.00(0.80-1.25)$ & $1.57(0.83-2.99)$ & $1.24(0.91-1.67)$ \\
\hline Cancer & $0.97(0.77-1.21)$ & $0.92(0.79-1.07)$ & $1.07(0.66-1.75)$ & $0.45(0.06-3.33)$ & $0.37(0.13-1.03)$ \\
\hline Renal failure & $0.94(0.78-1.14)$ & $1.07(0.94-1.22)$ & $1.56(1.11-2.17)$ & $1.81(0.75-4.37)$ & $1.44(0.92-2.24)$ \\
\hline $\begin{array}{l}\text { Anemia or other } \\
\text { hematologic disease }\end{array}$ & $1.14(1.01-1.28)$ & $0.94(0.87-1.02)$ & $1.23(0.97-1.58)$ & $1.25(0.63-2.46)$ & $1.53(1.11-2.10)$ \\
\hline \multicolumn{6}{|l|}{ Cardiovascular procedure } \\
\hline Angioplasty & $7.23(6.36-8.22)$ & $9.28(8.45-10.20)$ & $0.88(0.49-1.59)$ & $0.56(0.22-1.47)$ & $0.83(0.59-1.15)$ \\
\hline \multicolumn{6}{|l|}{ Prior gastrointestinal event } \\
\hline $\begin{array}{l}\text { Diagnosis of peptic ulcer } \\
\text { disease }\end{array}$ & $1.48(0.96-2.28)$ & $0.97(0.70-1.34)$ & $2.09(0.90-4.85)$ & NAt & $0.94(0.22-4.00)$ \\
\hline Visit to gastroenterologist & $0.85(0.73-0.99)$ & $0.81(0.73-0.90)$ & $0.89(0.65-1.22)$ & $1.65(0.76-3.58)$ & $1.06(0.71-1.58)$ \\
\hline \multicolumn{6}{|l|}{ Use of gastroprotective agent } \\
\hline Proton pump inhibitor & $1.79(1.63-1.98)$ & $1.39(1.30-1.49)$ & $1.22(0.98-1.52)$ & $1.24(0.66-2.33)$ & $1.26(0.96-1.67)$ \\
\hline $\begin{array}{l}\text { Histamine-2 receptor } \\
\text { antagonist }\end{array}$ & $0.69(0.57-0.84)$ & $0.57(0.50-0.65)$ & $0.91(0.63-1.32)$ & $0.32(0.04-2.38)$ & $0.67(0.34-1.33)$ \\
\hline \multicolumn{6}{|l|}{ Prior bleeding } \\
\hline $\begin{array}{l}\text { Non-gastrointestinal } \\
\text { bleeding necessitating } \\
\text { hospital admission }\end{array}$ & $0.69(0.33-1.44)$ & $0.61(0.14-2.69)$ & $0.61(0.35-1.07)$ & NAt & $1.94(0.41-9.07)$ \\
\hline \multicolumn{6}{|l|}{ Medication use in prior year } \\
\hline Antihyperglycemic agent & $1.28(1.16-1.42)$ & $0.95(0.88-1.02)$ & $1.07(0.84-1.37)$ & $1.10(0.56-2.17)$ & $1.63(1.21-2.19)$ \\
\hline Antihypertensive agent & $2.86(2.56-3.20)$ & $1.14(1.07-1.21)$ & $1.48(1.14-1.94)$ & $0.34(0.17-0.72)$ & $1.24(0.89-1.72)$ \\
\hline Antidepressant & $1.19(1.05-1.35)$ & $0.97(0.88-1.05)$ & $34.88(26.47-45.97)$ & $24.10(10.93-53.15)$ & $48.64(32.74-72.25)$ \\
\hline \multicolumn{6}{|l|}{ Medication use at discharge } \\
\hline Anticoagulant & $1.09(0.93-1.28)$ & $0.69(0.61-0.77)$ & $1.12(0.75-1.67)$ & $1.09(0.38-3.16)$ & $0.70(0.35-1.39)$ \\
\hline Corticosteroid & $0.65(0.45-0.93)$ & $0.93(0.76-1.15)$ & $1.83(1.15-2.91)$ & $3.32(0.96-11.47)$ & $1.66(0.84-3.29)$ \\
\hline
\end{tabular}

Note: $\mathrm{ASA}=$ acetylsalicylic acid, $\mathrm{Cl}=$ confidence interval, $\mathrm{NA}=$ not applicable, $\mathrm{OR}=$ odds ratio.

*Adjusted for cardiovascular surgery, coronary artery bypass surgery, hemorrhagic stroke, gastroscopy, use of nonselective nonsteroidal anti-inflammatory drug at discharge and use of cyclooxygenase-2 (COX-2) inhibitor at discharge.

tThe number of patients satisfying this condition was too low to allow inclusion of the variable in the model. 
4.85). When we assessed the risk of bleeding by SSRI affinity, the increased risk of bleeding associated with the use of high-affinity SSRIs compared with ASA alone was not significant (ASA and high-affinity SSRI v. ASA alone: 34 events; HR 1.29, 95\% CI 0.90-1.84; and ASA, clopidogrel and high-affinity SSRI v. ASA alone: 11 events; HR $1.56,95 \%$ CI 0.85-2.86. When we assessed intermediate-affinity SSRIs compared with ASA alone, the increased risk of bleeding was significant (ASA and intermediateaffinity SSRI: 27 events; HR 1.48, 95\% CI 1.002.18; and ASA, clopidogrel and intermediateaffinity SSRI: 20 events; HR 3.02, 95\% CI 1.92-4.75). When we compared the combined use of intermediate-affinity SSRIs and single or dual antiplatelet therapy with the combined use of high-affinity SSRIs and single or dual antiplatelet therapy, we found no statistically significant difference in the associated risk of bleeding.

Analyses investigating the risk of bleeding associated with antidepressants other than SSRIs did not reveal any increased risk. The results of the main analysis did not change significantly when we excluded patients who had any bleeding episode in the year before the index admission, or when we excluded patients who used clopidogrel, a proton pump inhibitor and either fluoxetine or sertraline. Removal of anticoagulant use from the model or adjusting for Charlson Comorbidity Index scores did not alter the results significantly either.

\section{Interpretation}

Patients taking an SSRI together with ASA or dual antiplatelet therapy following acute myocardial infarction were at increased risk of bleeding. Our findings showed that the use of ASA or clopidogrel alone was associated with a similar risk of bleeding. Compared with ASA alone, the combined use of an SSRI and ASA was associ- ated with a $42 \%$ increase in risk, and the combined use of clopidogrel and ASA was associated with a $49 \%$ increase in risk. The addition of an SSRI to dual antiplatelet therapy (ASA and clopidogrel) increased the risk by $57 \%$ compared with dual antiplatelet therapy alone. The risk of bleeding among patients taking clopidogrel and an SSRI was higher than that among patients taken clopidogrel alone, although the number of patients using this combination was not large enough to confirm the finding. These results did not vary by SSRI affinity or when we removed patients using drugs that may interact with clopidogrel (proton pump inhibitors, sertraline and fluoxetine).

As found in a previous study, ${ }^{31}$ age was an independent risk factor for bleeding necessitating hospital admission. Other independent risk factors were cancer, renal failure, congestive heart failure, anemia or other hematologic disease, history of peptic ulcer disease, prior use of antihypertensive agents or antihyperglycemic agents, use of anticoagulants or corticosteroids at discharge, visit to gastroenterologist in prior year and bleeding other than gastrointestinal bleeding or hemorrhagic stroke in prior year. Women appeared to have a decreased risk of bleeding, as did patients who underwent angioplasty during the index admission.

The crude rates of bleeding associated with ASA use and with clopidogrel and ASA use in our study were lower than the rates of bleeding found in the CURE (Clopidogrel in Unstable Angina to Prevent Recurrent Events) study (2.7\% among those taking placebo and ASA, and 3.7\% among those taking clopidogrel and ASA for at most 12 months, which implies that the rates per 100 patient-years would be even higher). ${ }^{32}$ This is surprising when one considers that the CURE study excluded patients at high risk of bleeding. The long follow-up of our study and perhaps the noncompliance of patients with the prescription regimen may have had an impact on the low event rate. If indeed the rate of bleeding is more

Table 3: Crude rate of bleeding episodes per 100 patient-years, by antiplatelet therapy at discharge and receipt of selective serotinin reuptake inhibitor (SSRI)

\begin{tabular}{|lccrcrc|}
\hline Exposure category & $\begin{array}{c}\text { No. of episodes } \\
\text { of exposure to } \\
\text { study drugs }\end{array}$ & $\begin{array}{c}\text { Duration of } \\
\text { treatment, } \\
\text { patient-years }\end{array}$ & $\begin{array}{c}\text { No. of bleeding episodes } \\
\text { in-hospital (rate per } \\
100 \text { patient-years, 95\% Cl) }\end{array}$ & $\begin{array}{c}\text { No. of hospital admissions } \\
\text { due to Gl bleeding (rate per } \\
100 \text { patient-years; 95\% Cl) }\end{array}$ \\
\hline ASA & 38310 & 61316 & 683 & $(1.12,1.03-1.20)$ & 399 & $(0.65,0.59-0.72)$ \\
\hline Clopidogrel & 5265 & 3609 & 56 & $(1.55,1.19-2.02)$ & 38 & $(1.05,0.77-1.45)$ \\
\hline ASA + clopidogrel & 21971 & 11146 & 232 & $(2.08,1.83-2.37)$ & 150 & $(1.35,1.15-1.58)$ \\
\hline ASA + SSRI & 7907 & 3777 & 61 & $(1.61,1.26-2.08)$ & 36 & $(0.95,0.69-1.32)$ \\
\hline ASA + clopidogrel + SSRI & 2260 & 855 & 31 & $(3.63,2.55-5.16)$ & 23 & $(2.69,1.79-4.05)$ \\
\hline Clopidogrel + SSRI & 736 & 288 & 7 & $(2.43,1.16-5.10)$ & 3 & $(1.04,0.34-3.23)$ \\
\hline Note: ASA = acetylsalicylic acid, Cl = confidence interval, GI = gastrointestinal. & & & & &
\end{tabular}




\begin{tabular}{|c|c|c|c|}
\hline Exposure category & HR $(95 \% \mathrm{CI})$ & $\longleftarrow \begin{array}{r}\text { Decreased risk } \\
\longleftarrow \quad \text { of bleeding }\end{array}$ & $\begin{array}{l}\text { Increased risk } \\
\text { of bleeding }\end{array}$ \\
\hline ASA (reference) & 1.00 & & \\
\hline Clopidogrel & $1.15(0.87-1.51)$ & & e- \\
\hline ASA + clopidogrel & $1.49(1.28-1.75)$ & & $\rightarrow$ \\
\hline$A S A+S S R I$ & $1.42(1.08-1.87)$ & & $\longrightarrow$ \\
\hline ASA + clopidogrel + SSRI & $2.35(1.61-3.42)$ & & $\longrightarrow$ \\
\hline Clopidogrel + SSRI & $1.76(0.83-3.73)$ & & $\bullet$ \\
\hline Clopidogrel + SSRI v. clopidogrel & $1.54(0.70-3.39)$ & & $\longrightarrow$ \\
\hline \multirow{2}{*}{$\begin{array}{l}\text { ASA + clopidogrel + SSRI } \\
\text { v. ASA + clopidogrel }\end{array}$} & $1.57(1.07-2.32)$ & & $\longrightarrow$ \\
\hline & & HR ( & $\% \mathrm{CI}$ \\
\hline
\end{tabular}

Figure 2: Association between exposure to medications under study and risk of bleeding among patients taking antiplatelet therapy following acute myocardial infarction (Cox regression model with time-dependent exposure). The model was adjusted for patient characteristics presented in Figure 3. Hazard ratios greater than 1.0 indicate an increased risk of bleeding. ASA = acetylsalicylic acid, $\mathrm{Cl}=$ confidence interval, $\mathrm{HR}=$ hazard ratio, $\mathrm{SSRI}=$ selective serotonin reuptake inhibitor.

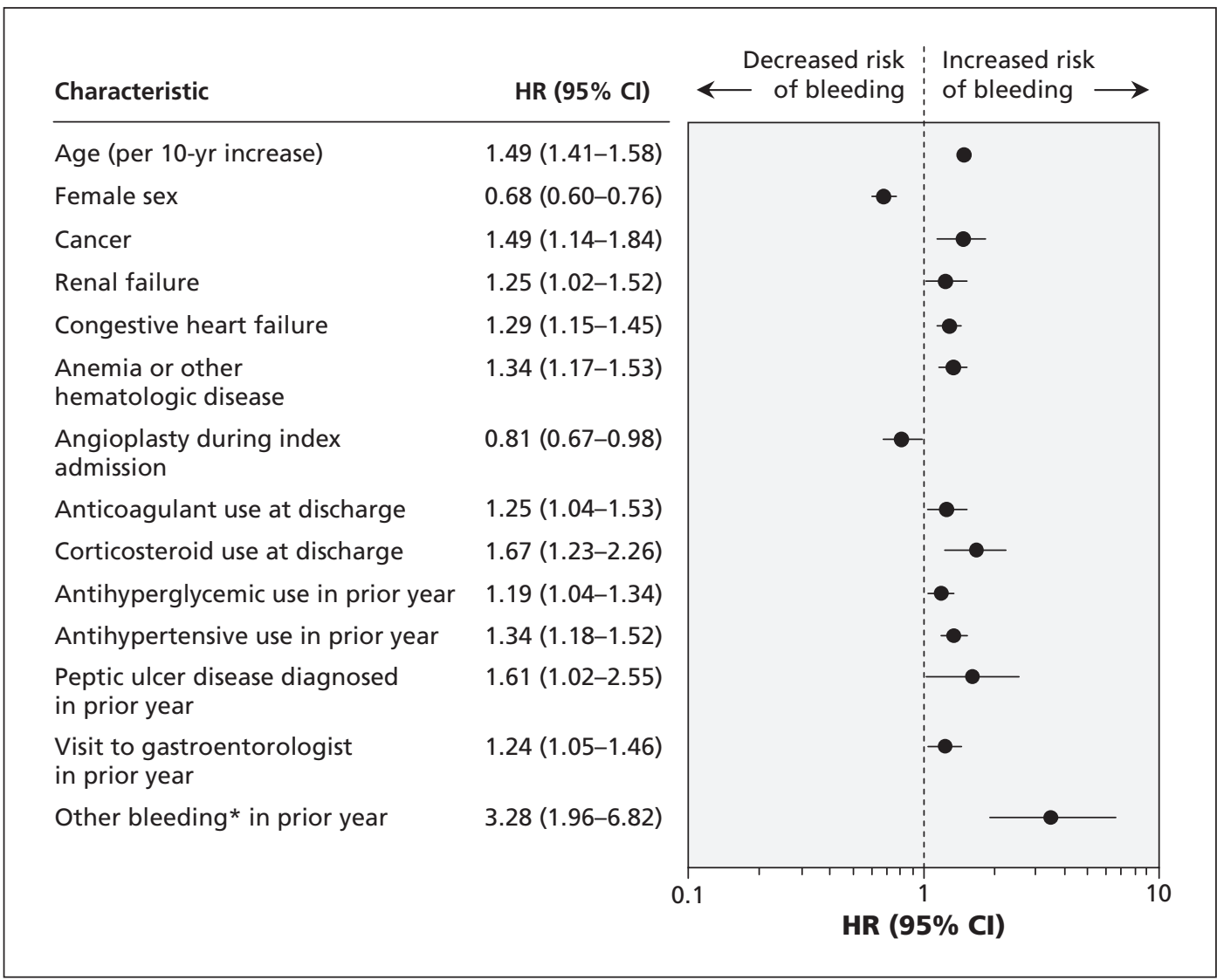

Figure 3: Patient characteristics associated with the risk of bleeding during follow-up (Cox regression model with time-dependent exposure). The model was adjusted for exposure to study drugs as presented in Figure 2, and for use of antidepressants other than selective serotonin reuptake inhibitors (SSRIs), use of $\mathrm{Hp}$-PAC to treat Helicobacter pylori infection in year before index admission, use of antiplatelet agents other than acetylsalicylic acid (ASA) and clopidogrel in year before index admission, and use of gastroprotective agents (proton pump inhibitors and histamine-2 receptor antagonists). A hazard ratio greater than 1.0 indicates an increased risk of bleeding. $\mathrm{Cl}=$ confidence interval, $\mathrm{HR}=$ hazard ratio. *Bleeding other than gastrointestinal bleeding or hemorrhagic stroke during the year before the index admission. 
pronounced during the first month of treatment, as some studies have suggested, ${ }^{18}$ then a followup period stretching over several years would likely dilute this effect.

Some previous studies have reported an increased risk of bleeding associated with SSRIs with higher affinity to serotonin. ${ }^{25}$ In contrast, we found similar risks of bleeding for SSRIs of high and intermediate affinity, which suggests that affinity to serotonin did not play an important role in the drug interactions of SSRIs and antiplatelet agents. Inhibition of cytochrome $\mathrm{P} 450$ by certain SSRIs has also been associated with increased risk of drug interactions causing bleeding; ${ }^{21}$ however, this hypothesis could not be verified in our study because of the limited number of patients using combinations involving these SSRIs.

\section{Limitations}

Our study has several limitations. First, its design is observational in nature. Selection bias is a major issue in such studies because patients' physicians determine treatment after myocardial infarction based on the risk-benefit ratio of the medications for these patients. Although our model adjusted for patient characteristics at baseline, some selection bias may have remained because of possible differences in unmeasured characteristics, such as patient frailty. If this were true, it would have biased the results toward a lower effect.

Second, because antiplatelet therapy is recommended for use in all patients following acute myocardial infarction unless contraindicated because of a high risk of adverse events, we did not include patients who were not using antiplatelet therapy.

Third, it may be that patients at increased risk of bleeding are more likely to have depression and require antidepressant therapy. Although our model adjusted for patient risk factors, residual bias may have remained.

Fourth, we depended on physician billing information to ascertain the patients' history of bleeding episodes in the year before the index admission. Minor bleeds often resolve on their own, and some physicians may not have included the diagnosis code on the bill for some episodes of bleeding before the index admission. If such patients were not prescribed dual antiplatelet therapy because of their increased risk of bleeding, misclassification might have biased our results toward a lower effect of dual antiplatelet therapy.

Fifth, we did not account for the potential use of over-the-counter ASA. However, because we included only patients who were taking prescribed antiplatelet therapy, these patients likely did not use over-the-counter ASA because they had finan- cial incentives to use the prescribed medication.

Finally, our analysis established only that patients filled their prescriptions, not that they took their medications. Our inability to confirm compliance with the prescribed treatment regimens is a potential source of bias.

\section{Conclusion}

Use of an SSRI with any form of antiplatelet therapy (ASA or clopidogrel, or both) was associated with an increased risk of bleeding among patients following acute myocardial infarction, beyond the risk associated with the antiplatelet therapy alone. Ultimately, clinicians must weigh the benefits of SSRI therapy against the risk of bleeding in patients with major depression following acute myocardial infarction. Clinicians should exercise caution when prescribing SSRIs to their patients with major depression following acute myocardial infarction. The potential for drug interactions must be evaluated to guide the choice of medication.

\section{References}

1. Baigent C, Blackwell L, Collins R, et al. Aspirin in the primary and secondary prevention of vascular disease: collaborative meta-analysis of individual participant data from randomised trials. Lancet 2009;373:1849-60.

2. Anderson JL, Adams CD, Antman EM, et al. ACC/AHA 2007 guidelines for the management of patients with unstable angina/non ST-elevation myocardial infarction: a report of the American College of Cardiology/American Heart Association Task Force on Practice Guidelines (Writing Committee to Revise the 2002 Guidelines for the Management of Patients With Unstable Angina/Non ST-Elevation Myocardial Infarction). Developed in collaboration with the American College of Emergency Physicians, the Society for Cardiovascular Angiography and Interventions, and the Society of Thoracic Surgeons; endorsed by the American Association of Cardiovascular and Pulmonary Rehabilitation and the Society for Academic Emergency Medicine. Circulation 2007;116:e148-304.

3. Antman EM, Hand M, Armstrong PW, et al. 2007 focused update of the ACC/AHA 2004 guidelines for the management of patients with ST-elevation myocardial infarction: a report of the American College of Cardiology/American Heart Association Task Force on Practice Guidelines (2007 Writing Group to Review New Evidence and Update the ACC/AHA 2004 Guidelines for the Management of Patients With ST-Elevation Myocardial Infarction, writing on behalf of the 2004 Writing Committee). Developed in collaboration with the Canadian Cardiovascular Society; endorsed by the American Academy of Family Physicians. Circulation 2008;117:296-329.

4. Weil J, Colin-Jones D, Langman M, et al. Prophylactic aspirin and risk of peptic ulcer bleeding. BMJ 1995;310:827-30.

5. A randomised, blinded, trial of clopidogrel versus aspirin in patients at risk of ischaemic events (CAPRIE). CAPRIE Steering Committee. Lancet 1996;348:1329-39.

6. Chan FK, Ching JY, Hung LC, et al. Clopidogrel versus aspirin and esomeprazole to prevent recurrent ulcer bleeding. $N$ Engl J Med 2005;352:238-44.

7. Buresly K, Eisenberg MJ, Zhang X, et al. Bleeding complications associated with combinations of aspirin, thienopyridine derivatives, and warfarin in elderly patients following acute myocardial infarction. Arch Intern Med 2005;165:784-9.

8. Ariyo AA, Haan M, Tangen CM, et al. Depressive symptoms and risks of coronary heart disease and mortality in elderly Americans. Cardiovascular Health Study Collaborative Research Group 1. Circulation 2000;102:1773-9.

9. Carney RM, Rich MW, Freedland KE, et al. Major depressive disorder predicts cardiac events in patients with coronary artery disease. Psychosom Med 1988;50:627-33.

10. Frasure-Smith N, Lesperance F, Talajic M. Depression following myocardial infarction. Impact on 6-month survival. JAMA 1993; 270:1819-25. 
11. Frasure-Smith N, Lesperance F, Talajic M. Depression and 18month prognosis after myocardial infarction. Circulation 1995;91: 999-1005.

12. Ladwig KH, Kieser M, Konig J, et al. Affective disorders and survival after acute myocardial infarction. Results from the postinfarction late potential study. Eur Heart J 1991;12:959-64.

13. Lespérance F, Frasure-Smith N, Juneau M, et al. Depression and 1-year prognosis in unstable angina. Arch Intern Med 2000;160: 1354-60.

14. Strik JJ, Honig A, Lousberg R, et al. Efficacy and safety of fluoxetine in the treatment of patients with major depression after first myocardial infarction: findings from a double-blind, placebo-controlled trial. Psychosom Med 2000;62:783-9.

15. Meier CR, Schlienger RG, Jick H. Use of selective serotonin reuptake inhibitors and risk of developing first-time acute myocardial infarction. Br J Clin Pharmacol 2001;52:179-84.

16. Welin C, Lappas G, Wilhelmsen L. Independent importance of psychosocial factors for prognosis after myocardial infarction. J Intern Med 2000;247:629-39.

17. Cohen HW, Gibson G, Alderman MH. Excess risk of myocardial infarction in patients treated with antidepressant medications: association with use of tricyclic agents. Am J Med 2000; 108:2-8.

18. Dalton SO, Johansen C, Mellemkjaer L, et al. Use of selective serotonin reuptake inhibitors and risk of upper gastrointestinal tract bleeding: a population-based cohort study. Arch Intern Med 2003; 163:59-64.

19. Andrade C, Sandarsh S, Chethan KB, et al. Serotonin reuptake inhibitor antidepressants and abnormal bleeding: a review for clinicians and a reconsideration of mechanisms. J Clin Psychiatry 2010;71:1565-75.

20. Horiuchi H. Recent advance in antiplatelet therapy: the mechanisms, evidence and approach to the problems. Ann Med 2006; 38:162-72.

21. Schellander R, Donnerer J. Antidepressants: clinically relevant drug interactions to be considered. Pharmacology 2010;86:203-15.

22. Weisberg S. Applied linear regression (Wiley Series in Probability and Statistics). 3rd ed. Hoboken (NJ): John Wiley \& Sons; 2005. p. 216-7.

23. Liu K, Dyer AR. A rank statistic for assessing the amount of variation explained by risk factors in epidemiologic studies. Am J Epidemiol 1979; 109:597-606

24. Ake CF, Carpenter AL. Survival analysis with PHREG: using MI and MIANALYZE to accommodate missing data. Proceedings of the 10th annual Western Users of SAS Software, Inc., Users Group Conference; Cary, NC; 2002; SAS Institute Inc. Available: www.caloxy.com/papers/47-ImputedPHREG.pdf (accessed 2011 Sept. 8)

25. van Walraven C, Mamdani MM, Wells PS, et al. Inhibition of serotonin reuptake by antidepressants and upper gastrointestinal bleeding in elderly patients: retrospective cohort study. BMJ 2001;323:655-8.

26. Serebruany VL, Glassman AH, Malinin AI, et al. Platelet /endothelial biomarkers in depressed patients treated with the selective serotonin reuptake inhibitor sertraline after acute coronary events: the Sertraline AntiDepressant Heart Attack Randomized Trial (SADHART) Platelet Substudy. Circulation 2003;108:939-44.

27. Walsky RL, Astuccio AV, Obach RS. Evaluation of 227 drugs for in vitro inhibition of cytochrome P450 2B6. J Clin Pharmacol 2006;46:1426-38.

28. $\mathrm{Li} \mathrm{XQ}$, Andersson TB, Ahlstrom M, et al. Comparison of inhibitory effects of the proton pump-inhibiting drugs omeprazole, esomeprazole, lansoprazole, pantoprazole, and rabeprazole on human cytochrome P450 activities. Drug Metab Dispos 2004;32:821-7.

29. Kurihara A, Hagihara K, Kazui M. In vitro metabolism of antiplatelet agent clopidogrel: cytochrome P450 isoforms responsible for two oxidation steps involved in the active metabolite formation. Drug Metab Rev 2005;37(Suppl 2):99.

30. Quan H, Sundararajan V, Halfon P, et al. Coding algorithms for defining comorbidities in ICD-9-CM and ICD-10 administrative data. Med Care 2005;43:1130-9.

31. de Abajo FJ, Rodriguez LA, Montero D. Association between selective serotonin reuptake inhibitors and upper gastrointestinal bleeding: population based case-control study. BMJ 1999;319: 1106-9.

32. Yusuf S, Zhao F, Mehta SR, et al. Effects of clopidogrel in addition to aspirin in patients with acute coronary syndromes without ST-segment elevation. N Engl J Med 2001;345:494-502.
Affiliations: From the Department of Medicine (Labos, Dasgupta, Rahme), McGill University, Montréal, Que.; the Division of Clinical Epidemiology (Dasgupta, Nedjar, Rahme), Research Institute, McGill University Health Centre, Montréal, Que.; and the Department of Psychiatry (Turecki), Douglas Hospital Research Institute, McGill University, Montréal, Que.

Contributors: Christopher Labos participated in the design of the study, the selection of relevant ICD codes and the interpretation of results; he wrote the first draft of the manuscript. Kaberi Dasgupta participated in the design of the study, interpretation of results and writing of the manuscript. Hacene Nedjar conducted the statistical analyses and participated in the writing of the manuscript. Gustavo Turecki provided expertise in use of antidepressants and mechanism of adverse effects; he participated in the interpretation of results and writing of the manuscript. Elham Rahme obtained the data, participated in the design of the study, supervised the analyses and participated in the writing and revisions of the manuscript. All of the authors approved the final version of the manuscript submitted for publication.

Funding: The authors did not receive financial support for this study.

Acknowledgements: Elham Rahme and Gustavo Turecki are senior research scholars of the Fonds de la Recherche en Santé du Québec. Kaberi Dasgupta is a physician-scientist funded by the Canadian Institutes of Health Research. 